\title{
Meniscal Cyst
}

National Cancer Institute

\section{Source}

National Cancer Institute. Meniscal Cyst. NCI Thesaurus. Code C96205.

A cyst located at the periphery of the meniscus. 